\title{
DESEMPENHO DE LINHAGENS DE TRIGO, ORIUNDAS DE HIBRIDAÇÕES, EM DUAS CONDIÇÕES DE CULTIVO DO ESTADO DE SÃO PAULO E TOLERÂNCIA À TOXICIDADE DE ALUMÍNIO EM LABORATÓRIO (1)
}

\author{
CARLOS EDUARDO DE OLIVEIRA CAMARGO $\left({ }^{*}, 6\right)$; ANTONIO WILSON PENTEADO \\ FERREIRA FILHO $\left({ }^{2}\right)$; JOÃO CARLOS FELICIO $\left({ }^{2}\right)$; PAULO BOLLER GALLO $\left({ }^{3}\right)$; MARY TÚLIA \\ VARGAS LOBATO $\left({ }^{4}\right)$; GUSTAVO BARNABÉ BIUDES $\left({ }^{5}\right)$
}

\begin{abstract}
RESUMO
Compararam-se 18 linhagens provenientes de cruzamentos entre genótipos de trigo comum (Triticum aestivum L.) e entre genótipos de trigo comum e de trigo duro (T. durum L.), e as cultivares-controle IAC24 e IAC-370 em experimentos instalados em condição de sequeiro e solo ácido de Capão Bonito, e em condição de irrigação por aspersão e solo ácido com aplicação de calcário de Mococa, no período 20032005. Analisaram-se produção de grãos, outros componentes da produção, características agronômicas e resistência ao agente causal da ferrugem-da-folha. Estudou-se também a tolerância ao alumínio em soluções nutritivas, no laboratório. As linhagens 9 (IAC-24/Anahuac M - Tol Al) e 14 (BH-1146// AA"S" / WIN"S"/3/G.C.W1/SERI) destacaram-se quanto à produção de grãos em Mococa e a linhagem 10 (IAC24/Anahuac $\mathrm{M}$ - Tol Al), tolerante à toxicidade de $\mathrm{Al}^{3+}$, em soluções nutritivas, sobressaíu-se quanto à produção de grãos, apresentando as plantas semi-anãs mais altas, em Capão Bonito. Todos os genótipos tiveram porte semi-anão e a cultivar IAC-370 e as linhagens 13 (BH-1146// AA"S" / WIN"S"/3/IAC-287), 14 e 15 F12.71/COC// CMH76.173/CMH 75 A 66/3/Desconhecido exibiram resistência ao acamamento. As linhagens 13 e 14 pela baixa incidência da ferrugem-da-folha mostraram ser boas fontes de resistência a essa doença em programas de melhoramento genético. As linhagens 17, 18, 19 e 20, oriundas do cruzamento interespecífico Maya "S" /SPRW"S" / /SAP“S" /3/BUC"S" / 4/IAC-225/5/IAC-1003 tiveram espigas compridas associadas aos grãos pesados, a linhagem 3 (IAC-24/Siete Cerros) destacaram-se em relação ao número de grãos por espiga e por espigueta e a linhagem 14 pelo número de espiguetas por espiga. As cultivares IAC-24 e BH-1146, e as linhagens 4, 5, 6, 7, 8 e 10, selecionadas a partir do híbrido

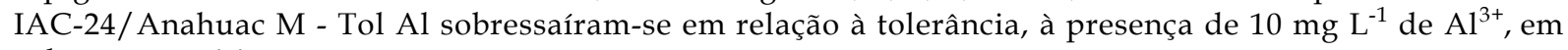
soluções nutritivas.
\end{abstract}

Palavras-chave: Triticum aestivum L., produção de grãos, características agronômicas, resistência à ferrugemda-folha.

( $\left.{ }^{1}\right)$ Recebido para publicação em 22 de fevereiro de 2007 e aceito em 7 de fevereiro de 2008.

$\left({ }^{2}\right)$ Instituto Agronômico (IAC), Centro de Análise e Pesquisa Tecnológica do Agronegócio de Grãos e Fibras, Caixa Postal 28, 13012-970 Campinas (SP). E-mail: ccamargo@iac.sp.gov.br $\left(^{*}\right)$ Autor correspondente.

$\left({ }^{3}\right)$ Pólo Regional de Desenvolvimento Tecnológico dos Agronegócios do Nordeste Paulista, Caixa Postal 58, 13730-970, Mococa (SP).

$\left({ }^{4}\right)$ Bolsista de doutorado da FAPESP.

$\left({ }^{5}\right)$ Bolsista de mestrado da FAPESP.

$\left({ }^{6}\right)$ Com bolsa de produtividade em pesquisa do CNPq. 


\title{
ABSTRACT \\ PERFORMANCE OF WHEAT LINES IN TWO TILLAGE CONDITIONS OF STATE OF SÃO PAULO AND THEIR TOLERANCE TO ALUMINUM TOXICITY
}

\begin{abstract}
Eighteen inbred lines originated from crosses between bread wheat genotypes (Triticum aestivum L.) and between bread and durum (T. durum L.) genotypes, control cultivars IAC-24 and IAC-370 and were evaluated in experiments carried out under dryland and acid soil conditions in Capão Bonito and under sprinkler irrigation and limed soil conditions, in Mococa, in 2003-2005. Grain yield, yield components, agronomic characteristics and resistance to the causal agent of leaf rust were evaluated. The assayed genotypes were also evaluated for tolerance to Al toxicity in nutrient solutions. The inbred lines 9 (IAC-24/Anahuac M - Tol Al) and 14 (BH-1146/ / AA"S" /WIN"S"/3/G.C.W1/ SERI) were superior for grain yield in Mococa and the inbred line 10 (IAC-24/Anahuac M - Tol Al), tolerant to Al toxicity, in nutrient solutions, presented good performance in relation to grain yield showing the tallest semidwarf plants, in Capão Bonito. All genotypes showed semidwarf plant type and the cultivar IAC-370 and the lines 13 (BH-1146//AA"S"/WIN"S"/3/IAC-287), 14 and 15 (F12.71/COC//CMH76.173/CMH 75 A 66/ 3 /Desconhecido) exhibited resistance to lodging. Lines 13 and 14 due to low incidence of leaf rust can be considered as good sources of resistance. Lines 17, 18, 19 and 20, originated from the interspecific cross Maya"S" /SPRW"S" / SAP"S" /3/BUC"S" / 4/IAC-225/5/IAC-1003 had long heads associated with heavy grains, line 3 (IAC-24/Siete Cerros) showed good performance for number of grain per spike and spikelet and line 14 for number of spikelets per spike. IAC-24 and BH-1146 cultivars and the inbred lines 4, 5, 6, 7, 8 and 10, selected from the hybrid IAC-24/Anahuac M - Tol presented high Al tolerance in the nutrient solutions.
\end{abstract}

Key words: Triticum aestivum L., grain yield, agronomic characteristics, leaf rust resistance.

\section{INTRODUÇÃO}

A produção de trigo no Estado de São Paulo foi de 140,1 mil toneladas, em 2004, obtendo incremento de $33,8 \%$, em relação à safra anterior (EMBRAPA, 2005). Para que ocorra o estabelecimento definitivo da triticultura paulista, há necessidade, ainda, de muita pesquisa visando ao aumento da produtividade, à redução dos custos de produção e melhoria da qualidade tecnológica dos grãos.

O programa de melhoramento genético de trigo do Instituto Agronômico (IAC), por meio de hibridações entre os genótipos adaptados às condições paulistas e os introduzidos do Centro Internacional de Melhoramento de Milho e Trigo (CIMMYT), México, de alto potencial produtivo, seguidas de seleções, tem obtido novas linhagens com maior produtividade e porte semi-anão, resistentes às doenças, tolerantes à toxicidade de alumínio e com melhores qualidades tecnológicas (CAMARGO e FERREIRA FilHo, 2000). Muitas dessas linhagens, após serem avaliadas em experimentos instalados em vários locais e anos, em diferentes condições de cultivo, foram recomendadas como novas cultivares para o Estado de São Paulo (EMBrapa, 2005).

A ferrugem-da-folha é uma doença comum do trigo no Estado de São Paulo, sendo causada pelo fungo Puccinia recondita f. sp. tritici. Em muitos trabalhos realizados no exterior e no Brasil, verificou-se a grande freqüência dessa doença, causando queda na produção
(CAmargo et al, 2001, 2003; ReIs et al., 2000; Khan et al., 1997; Goulart e Paiva, 1992; Barros et al., 2005).

Cruzamentos interespecíficos entre o trigo comum (Triticum aestivum L.) e o trigo duro (T. durum L.), realizados no IAC, originaram linhagens que se destacaram, principalmente, em relação à resistência ao agente causal da ferrugem-da-folha, à produção de grãos e à tolerância ao alumínio (LOBATO et al., 2007).

O emprego da irradiação gama em sementes da cultivar Anahuac, introduzida do CIMMYT, México, com elevada sensibilidade à toxicidade de alumínio, permitiu a seleção da linhagem mutante, Anahuac M, com elevada tolerância ao $\mathrm{Al}^{3+}$, podendo ser cultivada em solos ácidos (CAMARGo et al, 2000; Tulmann Neto, A. et al., 2001). Este genótipo está sendo empregado como genitor no programa de cruzamentos do IAC, originando linhagens promissoras que ainda necessitam ser avaliadas quanto ao seu potencial produtivo.

Foi constatado que, quando se incorporou maior tolerância genética ao alumínio tóxico, em germoplasma de trigo, não foram incorporados genes que reduziam o potencial de rendimento de grãos, quando avaliado em ambiente sem alumínio tóxico (Rosa et al., 1994). Resultados semelhantes foram obtidos por TULMANN NETO et al. (2001), ao verificar que linhagens tolerantes à toxicidade de alumínio não tiveram redução do potencial produtivo quando cultivadas em solos corrigidos e com irrigação por aspersão. 
O objetivo deste trabalho foi avaliar as linhagens provenientes de cruzamentos entre genótipos de trigo comum e entre genótipos de trigo comum e de trigo duro, em comparação com cultivares-controle, quanto à produção de grãos, altura das plantas, acamamento, resistência à ferrugem-dafolha, tolerância à toxicidade de alumínio e outras características agronômicas, em experimentos instalados em dois locais do Estado de São Paulo.

\section{MATERIAL E MÉTODOS}

Os experimentos foram instalados em dois locais do Estado de São Paulo: Capão Bonito (latitude $24^{\circ} 00^{\prime} \mathrm{S}$, longitude $48^{\circ} 22^{\prime} \mathrm{W}$ e altitude $702 \mathrm{~m}$ ) em condição de sequeiro e solo ácido, zona tritícola B e Mococa (latitude $21^{\circ} 28^{\prime} \mathrm{S}$, longitude $47^{\circ} 01^{\prime} \mathrm{W}$ e altitude $665 \mathrm{~m}$ ) em condição de irrigação por aspersão e solo corrigido, zona tritícola $\mathrm{H}$, durante o período de 2003 a 2005.

Foram avaliados 20 genótipos, sendo 18 linhagens e duas cultivares-controle IAC-24 (1) e IAC370 (2) (Tabela 1). Incluíram-se nos ensaios um genótipo (3) oriundo do cruzamento entre a cultivar IAC-24, recomendada para cultivo no Estado de São Paulo e a Siete Cerros, introduzida do CIMMYT, México, sete genótipos (4 a 10), provenientes de cruzamentos entre a cultivar IAC-24 e a linhagem mutante Anahuac, tolerante à toxicidade de alumínio, dois genótipos (11 e 12) provindos de cruzamentos entre as cultivares mexicanas Siete Cerros e Anahuac com a linhagem mutante Anahuac, dois genótipos (13 e 14) oriundos de cruzamentos entre a linhagem BH-1146// $\mathrm{AA}^{\prime \prime} \mathrm{S}^{\prime \prime}$ / WIN"S" e a cultivar IAC-287 e G.C.W1/SERI, ambas mexicanas. BH- 1146// AA"S" / WIN"S" é provinda do cruzamento entre a cultivar BH-1146 e uma linhagem de trigo duro, dois genótipos (15 e 16) oriundos de cruzamentos entre uma linhagem mexicana com um genótipo brasileiro desconhecido e com IAC-24, e quatro genótipos (17 a 20) provindos de cruzamentos interespecíficos envolvendo uma linhagem de trigo comum obtida no programa de melhoramento do IAC e a cultivar de trigo duro IAC-1003.

No experimento de campo, empregou-se o delineamento de blocos ao acaso, com quatro repetições. Cada ensaio foi constituído de 80 parcelas. Nos experimentos instalados em Capão Bonito, cada parcela foi formada de seis linhas, de $3 \mathrm{~m}$ de comprimento, espaçadas de $0,20 \mathrm{~m}$, totalizando 3,6 $\mathrm{m}^{2}$, as quais foram semeadas manualmente. A semeadura em Mococa foi feita por semeadeira de parcela, sendo cada parcela formada de oito linhas de $3 \mathrm{~m}$ de comprimento, espaçadas de 0,15 m, totalizando também 3,6 $\mathrm{m}^{2}$. Em todos os experimentos utilizaram-se cerca de 1.440 sementes viáveis por parcela. Deixou-se uma separação lateral de $0,60 \mathrm{~m}$ entre as parcelas, visando evitar que uma parcela constituída por plantas mais altas pudesse sombrear uma parcela próxima de porte de planta menor, prejudicando sua produção de grãos. Por ocasião da colheita, foram colhidas todas as linhas, seis ou oito, conforme o caso, de cada parcela $\left(3,6 \mathrm{~m}^{2}\right)$.

Coletaram-se os seguintes dados nos experimentos: altura das plantas, porcentagem de acamamento e produção de grãos. Para estimar o comprimento da espiga, o número de espiguetas, o número de grãos por espiga e por espigueta e a massa de cem grãos foram tomadas cinco espigas de cada parcela, de acordo com LOBATO, 2006, apenas nos experimentos de Mococa em 2004 e 2005. A avaliação dessas características foi feita conforme CAMARGO et al. (1995).

Os dados de produção de grãos, altura das plantas, comprimento da espiga, o número de espiguetas, o número de grãos por espiga e por espigueta e a massa de cem grãos de cada experimento foram inicialmente submetidos às análises individuais de variância. Efetuou-se, posteriormente, a análise conjunta de variância para a produção de grãos e altura da planta, nos experimentos instalados em Capão Bonito e Mococa, e para comprimento da espiga, o número de espiguetas, o número de grãos por espiga e por espigueta e a massa de cem grãos, somente nos experimentos instalados em Mococa, em 2004 e 2005, a fim de avaliar a ocorrência da interação dos genótipos com os anos em cada local. Para a comparação das médias dos genótipos, utilizou-se o teste de Tukey ao nível de 5\%.

Efetuou-se a avaliação da ferrugem-da-folha (Puccinia recondita f. sp. tritici.), em cada parcela, em pelo menos uma repetição de cada experimento, por observação geral nos colmos e nas folhas superiores das plantas, no estádio de início de maturação (estádios 11.1 e 11.2 da escala de Feekes-Large), em condições naturais de infecção.

Empregou-se a escala modificada de Cobb, para avaliação da resistência, conforme ilustração em Mетна (1993), que leva em conta a porcentagem de área infectada e o tipo de pústula, ou seja, a intensidade da doença e a reação da planta. Essa escala vai de 0 a $99 \%$ de área foliar infectada, complementada pelo tipo de reação: $S$ = suscetível (uredossoro grande, coalescente, sem necrose e sem clorose); $\mathrm{MS}=$ moderadamente suscetível (uredossoro médio); $\mathrm{M}$ = intermediário (diversos tipos de reação); $\mathrm{MR}=$ moderadamente resistente (uredossoro pequeno); $\mathrm{R}=$ resistente (uredossoro minúsculo, rodeado de áreas necróticas). 
As plântulas dos 20 genótipos e das cultivares-controle BH-1146 (tolerante) e Anahuac (sensível) foram testadas para tolerância ao alumínio, em condição de laboratório, nas doses de 0 , 2, 4, 6, 8 e $10 \mathrm{mg} \mathrm{L}^{-1}$ de $\mathrm{Al}^{3+}$, em soluções nutritivas, conforme CAMARgo (1984) e Moore et al. (1976).

O delineamento experimental empregado foi o de blocos ao acaso, com arranjo em parcelas subdivididas: as parcelas, compostas por seis concentrações de alumínio $\left(0,2,4,6,8\right.$ e $\left.10 \mathrm{mg} \mathrm{L}^{-1}\right)$, e as subparcelas, pelos 20 genótipos de trigo. Realizaram-se quatro repetições para cada soluçãotratamento. $\mathrm{Na}$ análise dos dados, considerou-se a média do comprimento da raiz primária central das cinco plântulas de cada genótipo, para cada repetição.

Após 48 horas nas soluções de tratamento contendo as diferentes concentrações de alumínio, os genótipos foram transferidos para soluções nutritivas completas sem alumínio por 72 horas. Aqueles que cresceram nesse meio foram considerados tolerantes; aqueles em que não houve crescimento das raízes foram considerados sensíveis.

Calcularam-se as correlações simples para os experimentos instalados em Capão Bonito e Mococa, no período de 2003-2005, entre as produções médias de grãos e os crescimentos médios das raízes dos genótipos, medidos após 72 horas de crescimento na solução nutritiva, que se seguiu ao da solução-tratamento contendo $2,4,6$, 8 e $10 \mathrm{mg} \mathrm{L}^{-1}$ de $\mathrm{Al}^{3+}$.

\section{RESULTADOS E DISCUSSÃO}

Os quadrados médios das análises individuais de variância para a produção de grãos dos genótipos estudados, em Capão Bonito e Mococa, no período de 2003-2005, foram significativos ao nível de $5 \%$, para genótipos, e não significativos para repetições (Tabela 1 ).

Os quadrados médios da análise de variância conjunta das produções de grãos dos genótipos avaliados nos três experimentos de Capão Bonito (2003-2005), instalados em condição de sequeiro e de solo ácido, revelaram efeitos significativos para anos, genótipos e para a interação genótipos $x$ anos (Tabela 1). Esses resultados não concordaram com os observados por CAMARGo et al. $(2003 ; 2006)$ que, analisando ensaios de avaliação de genótipos de trigo, em Capão Bonito, no período 1997-1999 e de 2001-
2002, verificaram efeitos significativos para anos e genótipos e não significativos para a interação genótipos $x$ anos.

Os autores ponderaram que apesar das diferenças climáticas ocorridas entre os anos, os genótipos proporcionaram, comparativamente, o mesmo comportamento, isto é, os mais produtivos no ano também tenderam ser os mais produtivos nos outros anos. No presente trabalho, os genótipos proporcionaram comportamento diferente em relação aos anos em que foram avaliados. Como os experimentos foram instalados em local muito próximo nos três anos o efeito da variável fertilidade do solo poderia ser minimizado. A interação poderia ser explicada pela diferente distribuição de chuvas nos três anos, considerando que o total de precipitação pluviométrica, no período de março a agosto, nos anos de 2003, 2004 e 2005 variaram de 434,1 mm, 445,2 mm e $496,4 \mathrm{~mm}$, respectivamente.

Os coeficientes de variação calculados para cada um dos ensaios instalados em Capão Bonito bem como, quando, esses ensaios analisados em conjunto foram altos, conforme Gomes (2000) (Tabela 1) indicando, portanto, a ocorrência de erros experimentais consideráveis. Esse fato pode ser explicado em virtude de o local estudado ter um solo originalmente ácido, nunca corrigido por calagem e, portanto, não uniforme, com variações, principalmente nos teores de alumínio e de bases (CAMARGo et al., 1997). Apesar disso, essa área experimental tem sido de grande utilidade para os trabalhos de melhoramento genético do trigo do IAC, onde são selecionadas linhagens tolerantes à toxicidade de alumínio. Mesmo com a redução da precisão dos experimentos os dados obtidos têm permitido com sucesso a separação dos genótipos mais produtivos e sensíveis a essa toxicidade (CAMARGo et al., 1997, 2005 e 2006; SALOMON et al., 2003).

Em 2003, não foram verificadas diferenças significativas entre os genótipos quando se aplicou o teste Tukey ao nível de 5\%. A linhagem $10(1.458 \mathrm{~kg}$ $\mathrm{ha}^{-1}$ ) destacou-se quanto à produção de grãos em Capão Bonito, em 2004, somente não diferindo da cultivar IAC-24 e das linhagens 4, 5, 6, 7, 9, 16 e 20 cujas produções de grãos variaram entre 986 e 1.319 $\mathrm{kg} \mathrm{ha}^{-1}$. No experimento instalado em 2005, as linhagens $4\left(2.115 \mathrm{~kg} \mathrm{ha}^{-1}\right)$ e $7\left(1.924 \mathrm{~kg} \mathrm{ha}^{-1}\right)$ foram as mais produtivas, somente diferindo da cultivar IAC-370 (688 kg ha $\left.{ }^{-1}\right)$ e das linhagens $12\left(899 \mathrm{~kg} \mathrm{ha}^{-1}\right)$, $17\left(938 \mathrm{~kg} \mathrm{ha}^{-1}\right), 18\left(861 \mathrm{~kg} \mathrm{ha}^{-1}\right)$ e $19\left(753 \mathrm{~kg} \mathrm{ha}^{-1}\right)$, menos produtivas.

Em solo ácido e condição de sequeiro de Capão Bonito, a linhagem 10 tolerante à toxicidade de alumínio, sobressaíu-se quanto à produção de grãos. 


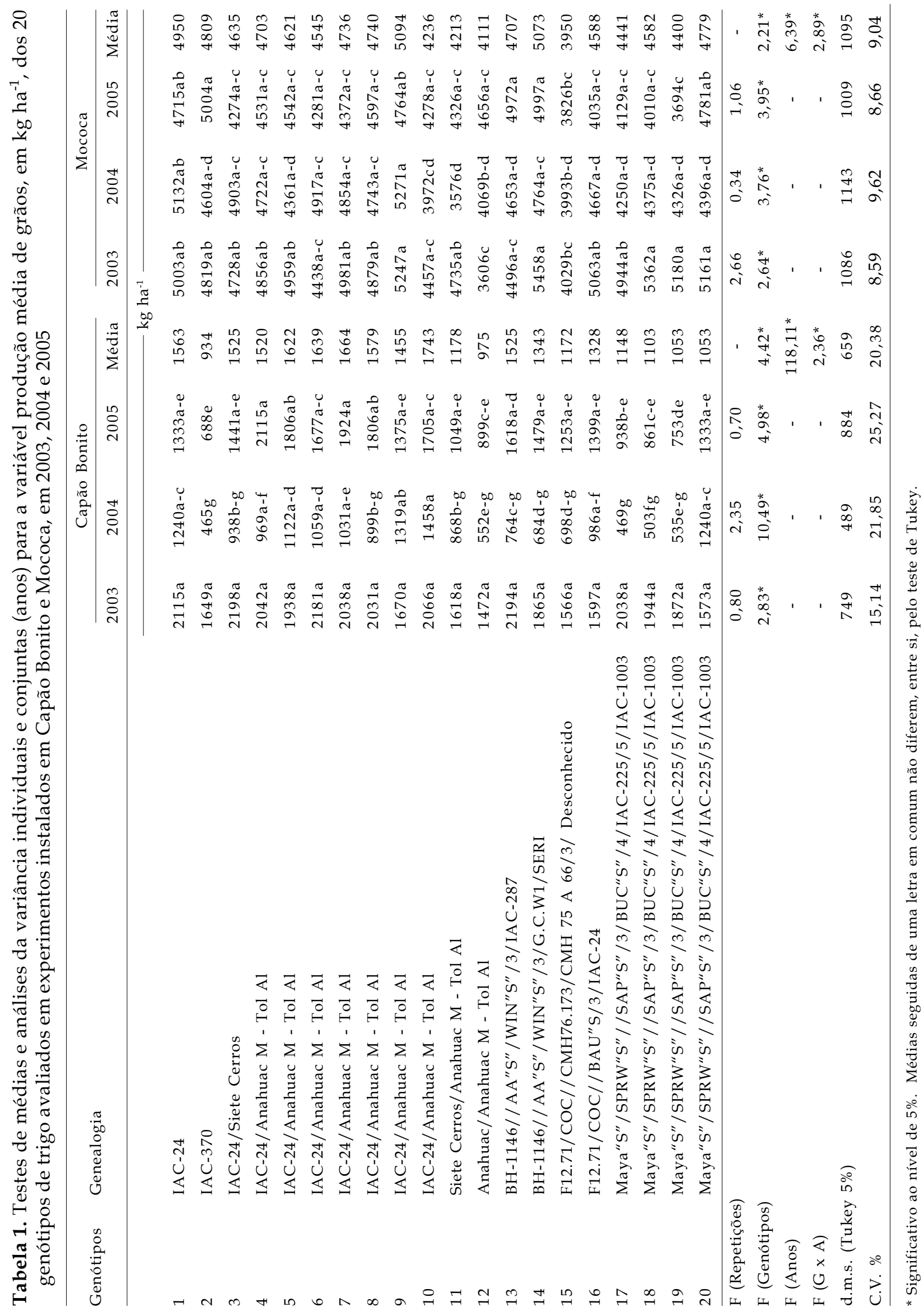


Os quadrados médios da análise de variância conjunta para as produções de grãos dos genótipos avaliados nos três experimentos de Mococa (20032005), utilizando-se irrigação por aspersão e solo corrigido pela calagem, foram significativos para anos, genótipos e para a interação genótipos $\mathrm{x}$ anos. Resultados semelhantes foram obtidos por LoвAто et al. (2005), avaliando linhagens diaplóides de trigo resultantes de hibridações, em Mococa, Tatuí e Ribeirão Preto, nos anos de 2003 e 2004. Considerando-se as médias do experimento instalado em Mococa, em 2003 (Tabela 1), as linhagens 9 (5.247 $\left.\mathrm{kg} \mathrm{ha}^{-1}\right), 14\left(5.458 \mathrm{~kg} \mathrm{ha}^{-1}\right), 18\left(5.362 \mathrm{~kg} \mathrm{ha}^{-1}\right), 19(5.180$ $\left.\mathrm{kg} \mathrm{ha}^{-1}\right)$ e $20\left(5.161 \mathrm{~kg} \mathrm{ha}^{-1}\right)$ foram as melhores, diferindo, porém, somente das linhagens $12(3.606 \mathrm{~kg}$ $\left.\mathrm{ha}^{-1}\right)$ e $15\left(4.029 \mathrm{~kg} \mathrm{ha}^{-1}\right)$, que foram as menos produtivas.

A linhagem $9\left(5.271 \mathrm{~kg} \mathrm{ha}^{-1}\right)$ destacou-se quanto à produção de grãos em Mococa, em 2004, somente diferindo das linhagens 10,11, 12 e 15, as menos produtivas, com produções de grãos variando de 3.576 a $4.069 \mathrm{~kg} \mathrm{ha}^{-1}$. No experimento instalado em 2005, a cultivar IAC-370 (5.004 $\left.\mathrm{kg} \mathrm{ha}^{-1}\right)$ e as linhagens $13\left(4.972 \mathrm{~kg} \mathrm{ha}^{-1}\right)$ e $14\left(4.997 \mathrm{~kg} \mathrm{ha}^{-1}\right)$ foram as mais produtivas, diferindo apenas das linhagens $15\left(3.826 \mathrm{~kg} \mathrm{ha}^{-1}\right)$ e $19\left(3.694 \mathrm{~kg} \mathrm{ha}^{-1}\right)$.

As linhagens 9 e 14 destacaram-se quanto à produção de grãos, em Mococa, condição de irrigação por aspersão, considerando-se os três anos.

Os quadrados médios das análises individuais de variância para a altura das plantas dos genótipos estudados em Capão Bonito e Mococa, em 2003-2005, foram significativos, ao nível de 5\%, para genótipos, com exceção dos ensaios de Capão Bonito (2003) e de Mococa (2004) e não significativos para repetições, em todos os experimentos (Tabela 2).

Os quadrados médios da análise de variância conjunta para a altura das plantas dos genótipos avaliados nos três experimentos de Capão Bonito e Mococa, em 2003-2005, foram significativos para genótipos e anos. Os efeitos foram significativos para a interação genótipos $\mathrm{x}$ anos apenas quando se consideraram os experimentos de Capão Bonito (Tabela 2).

Verificaram-se na linhagem 10 as plantas com maior estatura $(89 \mathrm{~cm})$ em Capão Bonito em 2004, não diferindo da cultivar IAC-24 e das linhagens 4, 5, 6, 8 e 9 com estatura variando de 78 a $83 \mathrm{~cm}$, diferindo dos demais genótipos, que foram os mais baixos entre os avaliados. No experimento de 2005, a linhagem 10 , que exibiu altura das plantas de $83 \mathrm{~cm}$ foi a mais alta diferindo somente da cultivar IAC-370 $(61 \mathrm{~cm})$ e das linhagens $11(69 \mathrm{~cm}), 15(64 \mathrm{~cm}), 19(60 \mathrm{~cm})$ e $20(69$ $\mathrm{cm})$ as mais baixas.
As linhagens 11 e 12, ambas com altura das plantas de $83 \mathrm{~cm}$, foram as mais altas, diferindo apenas das linhagens semi-anãs mais baixas: 15 (74 $\mathrm{cm})$ e $16(76 \mathrm{~cm})$, quando se consideraram em conjunto a média dos três experimentos instalados em Mococa. Linhagens baixas também foram identificadas por SALOMON et al. (2003) e CAMARGo et al. (2006), em ensaios avaliados em Capão Bonito e por LoBATo et al. (2005), em Mococa.

Embora tenha sido observada variabilidade genética para altura das plantas, todos os genótipos foram classificados como de porte semi-anão, mesmo considerando que em Capão Bonito ocorreram variações nas alturas médias das plantas de 64 a 80 $\mathrm{cm}$ e em Mococa de 74 a $83 \mathrm{~cm}$. Esse resultado era esperado levando-se em conta que os genitores utilizados nos cruzamentos que originaram as linhagens em estudo eram de porte semi-anão.

As linhagens 3, 4, 6, 8, 10, 11 e 12 exibiram as maiores porcentagens médias de acamamento (variando de $50 \%$ a $63 \%$ ) nos dois locais considerados, o que ficou mais evidenciado em Mococa. Por outro lado, a cultivar IAC-370 e as linhagens 13, 14 e 15 foram as mais resistentes com porcentagem máxima de acamamento de $25 \%$, quando foram considerados todos os experimentos semeados em Capão Bonito e Mococa (Tabela 3). A resistência ao acamamento expressa pela linhagem 15 foi associada às plantas mais baixas medidas em Mococa.

Os graus médios de infecção de ferrugem-dafolha nos genótipos avaliados nos experimentos de Capão Bonito e Mococa são apresentados na tabela 4. As linhagens $4,5,7,8,10,13,14$ e 16 foram moderadamente resistentes (МЕтHA, 1993), ou seja, com um grau de infecção entre $6 \%$ e $25 \%$, em pelo menos, um dos experimentos avaliados. Pela resistência observada (baixa severidade da doença) provinda do genitor BH-1146// AA"S" / WIN"S" (CAMARGO et al., 1995), em todos os experimentos considerados, sugeriuse que as linhagens 13 e 14, poderiam servir como fontes de resistência à ferrugem-da-folha, em programas de melhoramento. Os demais genótipos comportaram-se como suscetíveis, ou seja, com um grau de infecção entre $26 \%$ e $50 \%$, em pelo menos um dos experimentos.

Nos quadrados médios das análises conjuntas de variância para comprimento das espigas, número de espiguetas por espiga, número de grãos por espiga e por espigueta e massa de cem grãos dos genótipos dos ensaios de Mococa (2004 e 2005), para todas as características consideradas, observaram-se efeitos significativos para genótipos, exceto para grãos por espiga, para anos e para número de espiguetas por espiga. A interação genótipos $\mathrm{x}$ anos somente não foi significativa para comprimento da espiga e número de espiguetas por espiga (Tabela 5). 


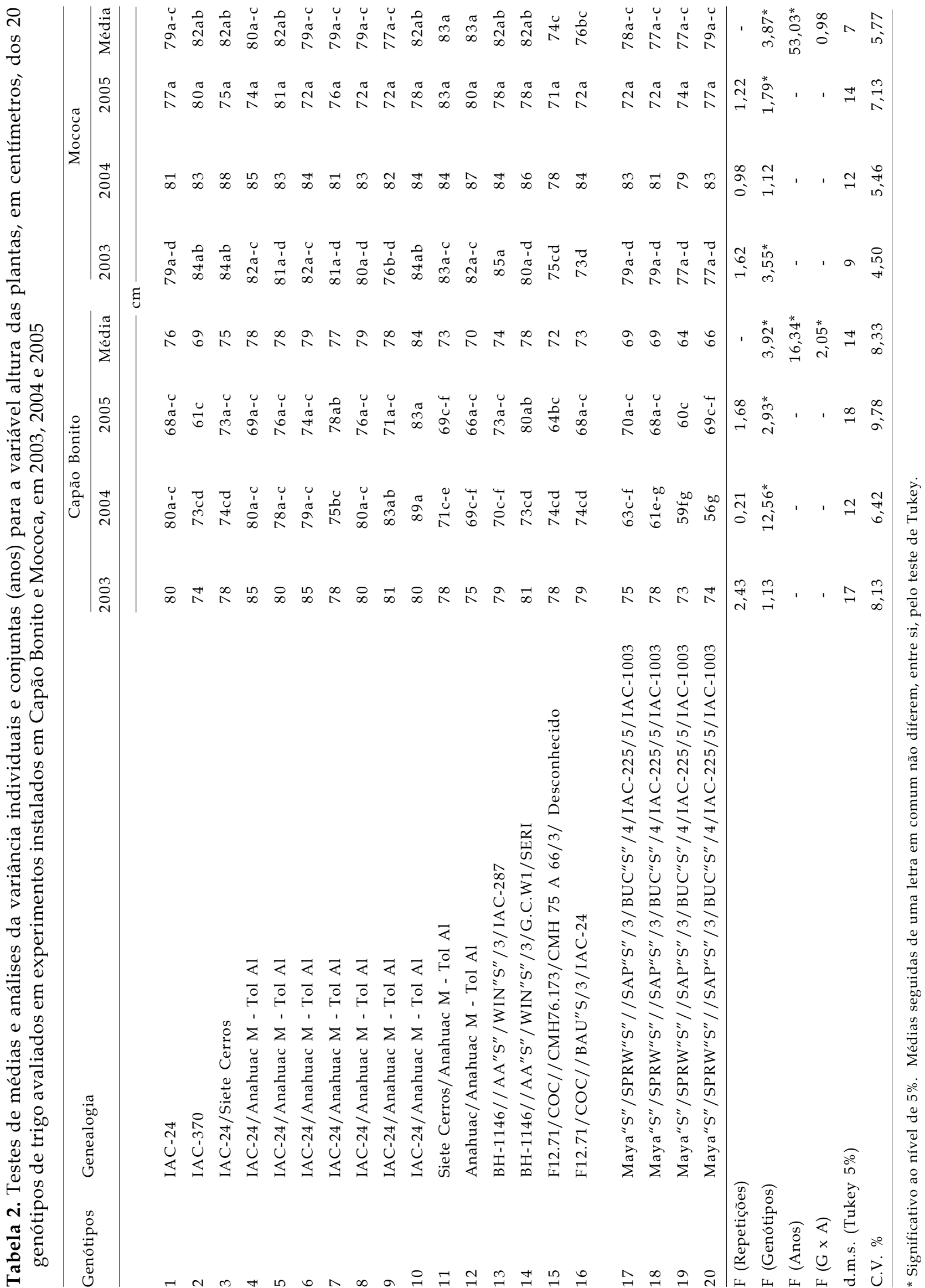




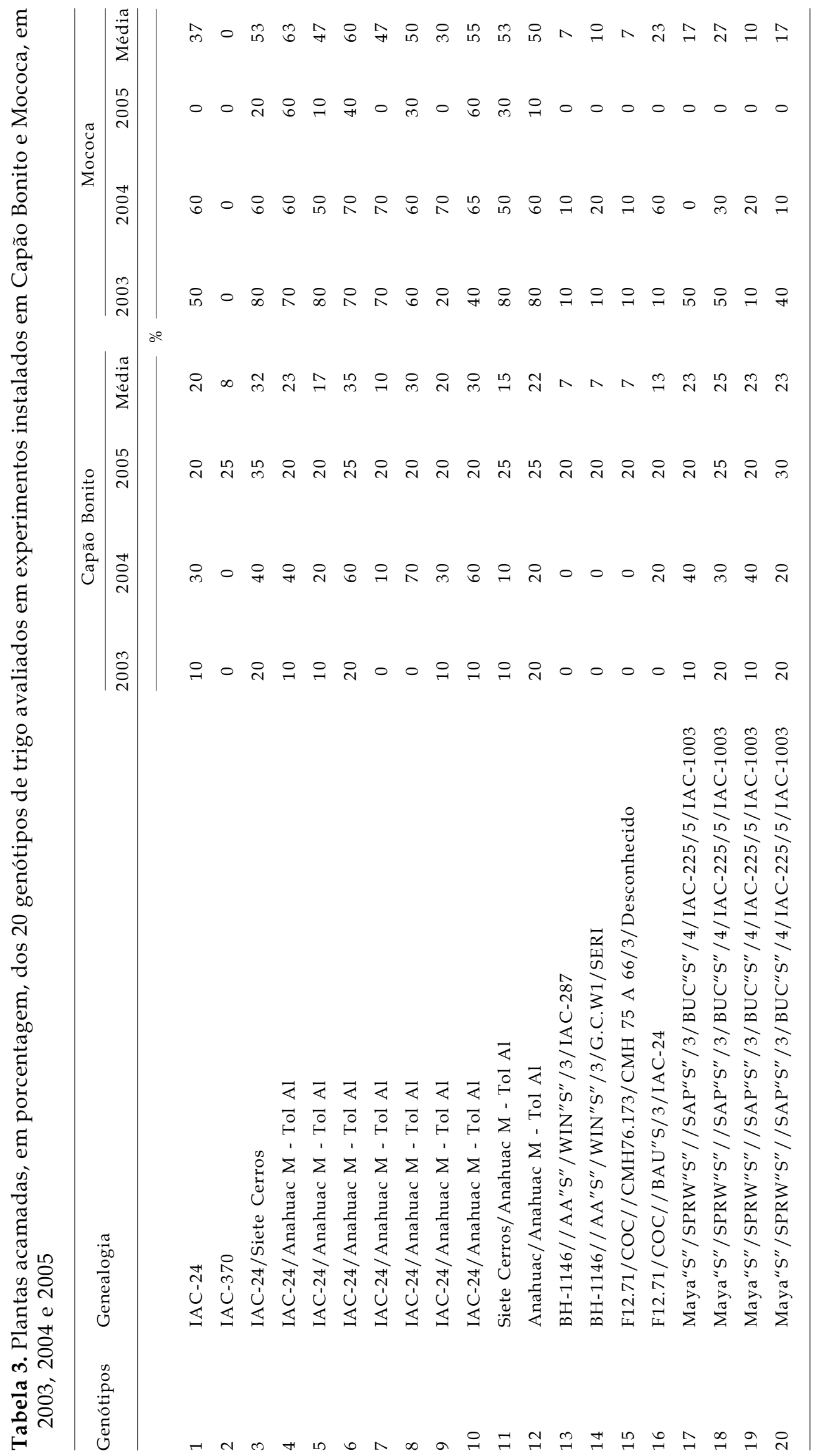




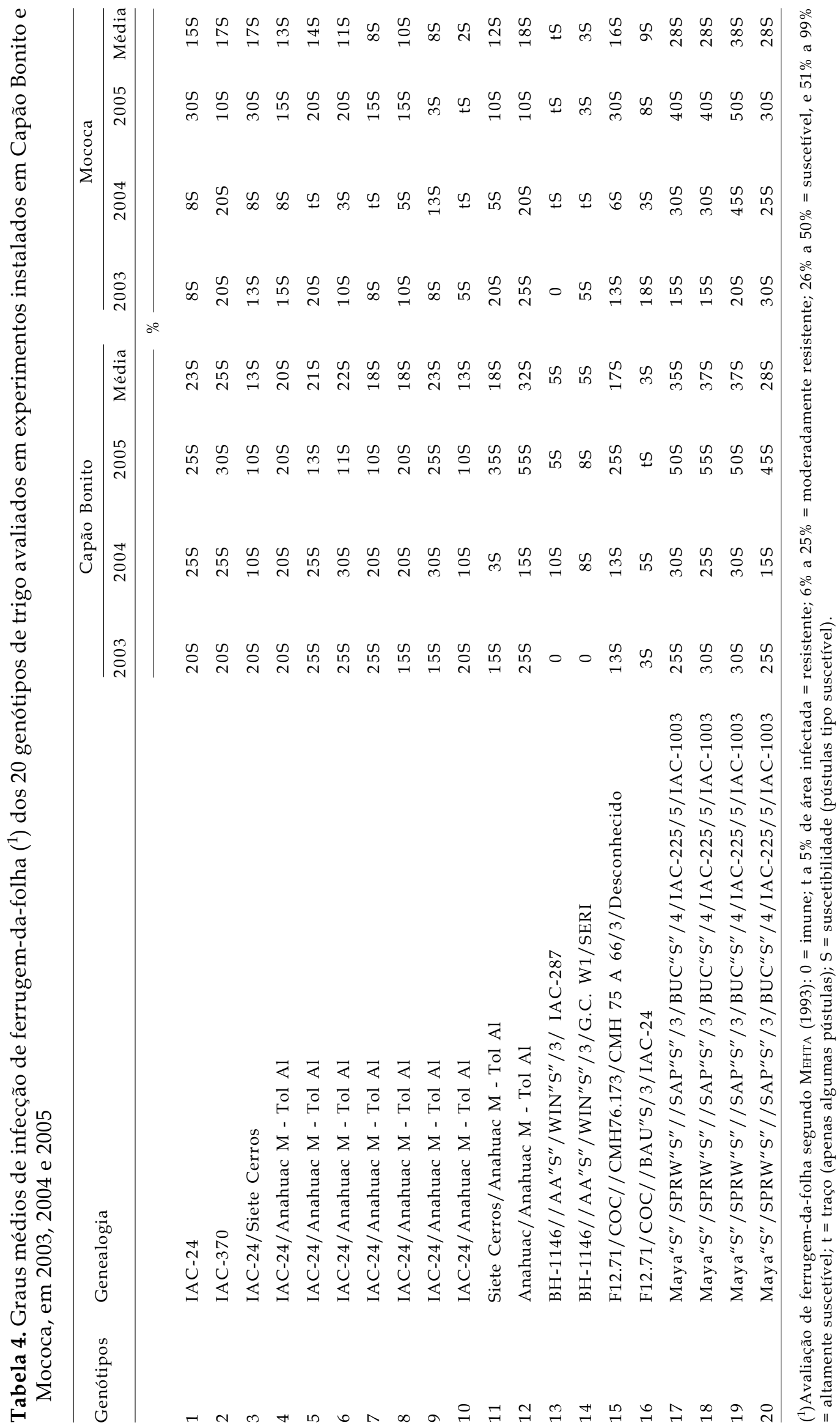




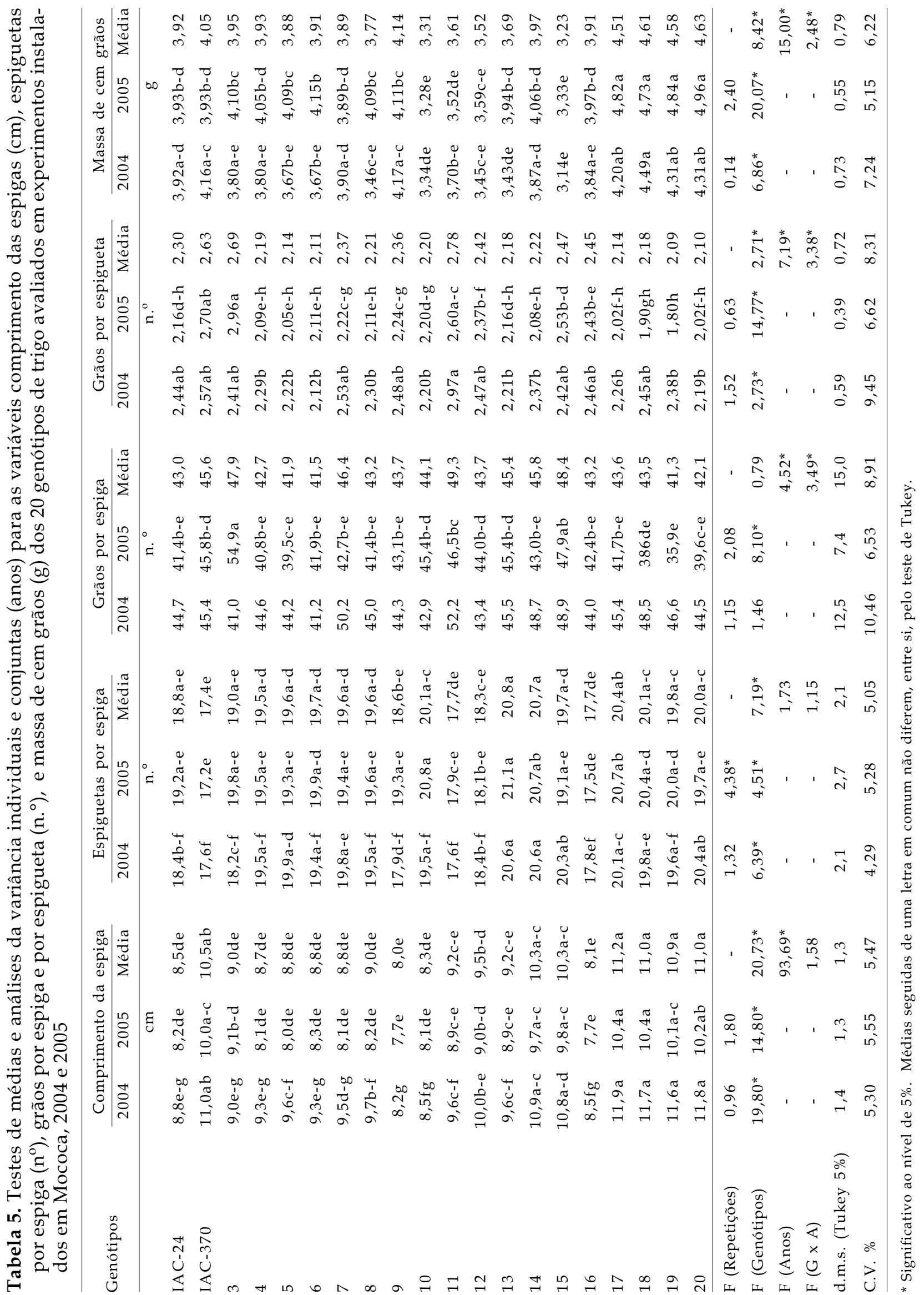


As linhagens 17, 18, 19 e 20, oriundas do híbrido Maya"S" /SPRW"S" / SAP"S" / / BUC"S" / 4/ IAC-225/5/IAC-1003 proporcionaram as espigas mais compridas, destacando-se também pelos grãos mais pesados. Por se observar, ao mesmo tempo, maior número de grãos por espiga e por espigueta, em 2005, a linhagem 3 revelou potencial para ser empregada como fonte genética dessas características no programa de cruzamentos do Instituto Agronômico.

As linhagens 13 e 14 destacaram-se em relação ao número de espiguetas por espiga, mas diferindo apenas, das linhagens 9, 11, 12 e 16 .

Observam-se na tabela 6 o comprimento médio das raízes dos 20 genótipos de trigo avaliados, além das cultivares-controle BH-1146 (tolerante) e Anahuac (sensível), após 72 horas de crescimento em solução normal (sem alumínio), que se seguiu a um crescimento em solução-tratamento contendo seis diferentes concentrações de alumínio, referente à média de quatro repetições.

Tabela 6. Comprimento médio $(\mathrm{mm})$ das raízes dos 20 genótipos de trigo avaliados nos experimentos, após 72 horas de crescimento em solução normal, que se seguiu a um crescimento em solução-tratamento contendo seis diferentes concentrações de alumínio (média de 4 repetições)

\begin{tabular}{|c|c|c|c|c|c|c|}
\hline \multirow{2}{*}{ Genótipos } & \multicolumn{6}{|c|}{ Concentração de alumínio $\left(\mathrm{mg} \mathrm{L}^{-1}\right)$} \\
\hline & 0 & 2 & 4 & 6 & 8 & 10 \\
\hline \multirow[b]{2}{*}{ IAC-24 } & & & $-n$ & 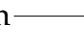 & & \\
\hline & 59,3 & 53,8 & 47,2 & 41,9 & 34,9 & 23,8 \\
\hline IAC-370 & 79,4 & 34,8 & 9,1 & 0,0 & 0,0 & 0,0 \\
\hline 3 & 81,6 & 55,5 & 36,5 & 19,2 & 14,3 & 3,1 \\
\hline 4 & 64,9 & 64,3 & 46,0 & 41,7 & 35,5 & 25,6 \\
\hline 5 & 72,9 & 56,3 & 50,8 & 38,0 & 32,8 & 24,9 \\
\hline 6 & 63,2 & 57,7 & 48,0 & 41,7 & 30,4 & 19,5 \\
\hline 7 & 63,0 & 65,2 & 45,3 & 41,0 & 28,7 & 26,5 \\
\hline 8 & 72,1 & 60,3 & 42,9 & 40,8 & 28,6 & 21,8 \\
\hline 9 & 74,8 & 66,6 & 47,9 & 36,1 & 30,4 & 11,2 \\
\hline 10 & 83,3 & 71,2 & 53,0 & 46,9 & 43,1 & 29,1 \\
\hline 11 & 81,2 & 66,1 & 47,2 & 37,6 & 30,7 & 14,0 \\
\hline 12 & 73,5 & 35,3 & 20,5 & 14,1 & 4,2 & 4,6 \\
\hline 13 & 76,1 & 34,8 & 19,7 & 1,8 & 1,7 & 0,0 \\
\hline 14 & 75,1 & 29,0 & 0,0 & 0,0 & 0,0 & 0,0 \\
\hline 15 & 66,3 & 49,6 & 22,1 & 0,1 & 1,3 & 0,0 \\
\hline 16 & 68,5 & 49,2 & 13,8 & 4,8 & 1,4 & 0,8 \\
\hline 17 & 83,4 & 57,5 & 28,0 & 5,0 & 4,6 & 0,7 \\
\hline 18 & 80,0 & 55,5 & 30,5 & 6,1 & 3,4 & 0,6 \\
\hline 19 & 74,2 & 56,5 & 29,4 & 5,2 & 3,2 & 2,1 \\
\hline 20 & 75,4 & 57,1 & 26,6 & 4,7 & 2,8 & 0,3 \\
\hline BH-1146 & 97,7 & 77,2 & 59,0 & 47,8 & 46,5 & 29,5 \\
\hline Anahuac & 76,6 & 0,0 & 0,0 & 0,0 & 0,0 & 0,0 \\
\hline
\end{tabular}

Verificou-se a diminuição do crescimento das raízes primárias centrais em praticamente todos os genótipos à medida que aumentaram as concentrações de alumínio.

Diferentes genótipos avaliados foram

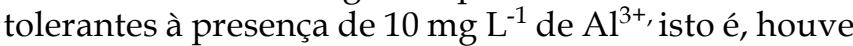
crescimento das raízes, após permanecerem 48 horas em soluções contendo $10 \mathrm{mg} \mathrm{L}^{-1}$ de $\mathrm{Al}^{3+}$, destacandose as cultivares IAC-24 e BH-1146, e as linhagens 4, 5, 6, 7, 8 e 10 oriundas do híbrido: IAC-24/Anahuac M - Tol Al. Fizeram exceção a cultivar-controle Anahuac (sensível à $2 \mathrm{mg} \mathrm{L}^{-1} \mathrm{de} \mathrm{Al}^{3+}$ ), a linhagem 14 (sensível à $4 \mathrm{mg} \mathrm{L}^{-1}$ de $\mathrm{Al}^{3+}$ ), a cultivar IAC-370 (sensível à $6 \mathrm{mg} \mathrm{L}^{-1}$ de $\mathrm{Al}^{3+}$ ) e as linhagens 13 e 15 (sensíveis à $10 \mathrm{mg} \mathrm{L}^{-1}$ de $\mathrm{Al}^{3+}$ ).

As correlações simples calculadas entre as produções médias de grãos dos 20 genótipos dos ensaios semeados em solo ácido de Capão Bonito e os comprimentos médios das raízes dos mesmos genótipos, medidos após 72 horas de crescimento na solução nutritiva, que se seguiu a crescimento na soluçã-tratamento, contendo 2 a $10 \mathrm{mg} \mathrm{L}^{-1} \mathrm{de} \mathrm{Al}^{3+}$, são apresentados na tabela 7. Dos resultados pode-se inferir que os genótipos mais adaptados (mais produtivos) às condições de solo ácido e cultivo de sequeiro foram tolerantes à toxicidade de $\mathrm{Al}^{3+}$, em soluções nutritivas, confirmando os dados obtidos por CAMARGo et al. (2003 e 2006).

Levando-se em consideração os experimentos de Mococa, as correlações simples calculadas entre as produções médias de grãos de cada genótipo e os respectivos crescimentos médios das raízes, medidos após 72 horas de crescimento na solução nutritiva, que se seguiu ao crescimento na solução-tratamento contendo diferentes concentrações de alumínio, foram não significativas (Tabela 7). Esses resultados permitem sugerir que os genótipos mais adaptados (mais produtivos) às condições de solo corrigido com calcário e com irrigação por aspersão independeram do grau de tolerância à toxicidade $\mathrm{de}^{\mathrm{Al}^{3+}}$, em soluções nutritivas.

Tabela 7. Estimativas das correlações simples entre as produções de grãos e os comprimentos das raízes nas diferentes concentrações de $\mathrm{Al}^{3+}$

\begin{tabular}{lcc}
\hline $\begin{array}{l}\text { Concentrações } \\
\text { de } \mathrm{Al}^{3+} \mathrm{em} \mathrm{mg} \mathrm{L}^{-1}\end{array}$ & $\begin{array}{c}\text { Capão Bonito } \\
2003-2005\end{array}$ & $\begin{array}{c}\text { Mococa } \\
2003-2005\end{array}$ \\
\hline 2 & 0,42 & $-0,11$ \\
4 & $0,63^{*}$ & $-0,05$ \\
6 & $0,73^{*}$ & 0,09 \\
8 & $0,75^{*}$ & 0,09 \\
10 & $0,76^{*}$ & 0,08 \\
\hline
\end{tabular}




\section{CONCLUSÕES}

1. Os genótipos avaliados nas condições de sequeiro e de solo ácido e de irrigação e de solo corrigido revelaram efeitos significativos para anos, genótipos e interação genótipos $x$ anos, caracterizando comportamento diferenciado, conforme os anos considerados.

2. Para as duas condições foram identificados genótipos superiores em relação à produção de grãos, altura das plantas, porcentagem de acamamento, resistência ao agente causal de ferrugem-da-folha, comprimento da espiga, número de espiguetas por espiga, número de grãos por espiga e por espigueta, massa de cem grãos.

3. Verificou-se a diminuição do crescimento das raízes primárias centrais em praticamente todos os genótipos à medida que aumentaram as concentrações de alumínio, em soluções nutritivas.

4. Genótipos muito tolerantes à toxicidade de $\mathrm{Al}^{3+}$ foram constatados, constituindo-se fontes genéticas dessa característica em programas de melhoramento.

5. Os genótipos mais produtivos nas condições de solo ácido e cultivo de sequeiro apresentaram-se tolerantes à toxicidade de $\mathrm{Al}^{3+}$, em soluções nutritivas.

\section{AGRADECIMENTOS}

Ao Conselho Nacional de Desenvolvimento Científico e Tecnológico (CNPq) pelo apoio financeiro ao projeto e pela concessão de bolsa de produtividade científica e à Fundação de Amparo à Pesquisa do Estado de São Paulo (FAPESP) pela concessão de bolsas de mestrado e doutorado.

\section{REFERÊNCIAS}

BARROS, B.C.; CASTRO,J.L.; PATRICIO, J.R.A. Resposta de cultivares de trigo ao controle químico das principais doenças fúngicas. Summa Phytopathologica, Botucatu, v.31, supl., p. 45, 2005.

CAMARGO, C.E.O. Melhoramento do trigo: VI. Hereditariedade da tolerância a três concentrações de alumínio em solução nutritiva. Bragantia, Campinas, v.43, n.2, p.279291, 1984 .

CAMARGO, C.E.O.; FELICIO, J.C.; FERREIRA FILHO, A.W.P.; BARROS, B.C.; PEREIRA, J.C.V.N.A.; PETTINELLI JUNIOR, A. Comportamento agronômico de linhagens de trigo no Estado de São Paulo. Bragantia, Campinas, v.60, n.1, p.35-44, 2001.
CAMARGO, C.E.O.; FELICIO, J.C.; TULMANN NETO, A.; FERREIRA FILHO, A.W.P.; PETTINELLI-JUNIOR, A.; CASTRO, J.L. Melhoramento de trigo: XXVIII. Novos genótipos obtidos por seleções em população segregante interespecífica submetida à irradiação gama. Bragantia, Campinas, v.54, n.1, p.51-65, 1995.

CAMARGO, C.E.O.; FERREIRA FILHO, A.W.P. São Paulo State, Brazil Wheat Pool. In: BONJEAN, A.P.; ANGUS, W.J.(Ed.). The world wheat book: a history of wheat breeding. Paris: Lavoisier, 2000. Cap. 21, p.549-577.

CAMARGO, C.E.O.; FERREIRA FILHO, A.W.P.; FELICIO, J.C.; RAMOS, L.C.S.; PETTINELLI JUNIOR, A.; FOLTRAN, D.E.; CASTRO, J.L.; LOBATO, M.T.V. Linhagens diaplóides de trigo: desempenho agronômico em dois locais do Estado de São Paulo e tolerancia à toxicidade de alumínio em laboratorio. Bragantia, Campinas, v.65, n.2, p.253-268, 2006.

CAMARGO, C.E.O.; FERREIRA FILHO, A.W.P.; RAMOS, L.C.S.; PETTINELLI JUNIOR, A.; CASTRO, J.L.; FELICIO, J.C.; SALOMON, M.V.; MISTRO, J.C. Comportamento de linhagens diaplóides de trigo em dois locais do Estado de São Paulo. Bragantia, Campinas, v.62, n.2, p.217-226, 2003.

CAMARGO, C.E.O.; FERREIRA FILHO, A.W.P.; TULMANN NETO, A.; PETTINELLI JUNIOR, A.; CASTRO, J.L.; FELICIO, J.C.; MISTRO, J.C.; SALOMON, M.V. Avaliação de linhagens de trigo originárias de hibridação com e sem irradiação gama. Bragantia, Campinas, v.64, n.1, p.61-74, 2005.

CAMARGO, C.E.O.; TULMANN NETO, A.; FERREIRA FILHO, A.W.P.; FELICIO, J.C. Genetic control of aluminum tolerance in mutant lines of the wheat cultivar Anahuac. Euphytica, Dordrecht, v.114, p.47-53, 2000.

CAMARGO, C.E.O.; TULMANN NETO, A.; FERREIRA FILHO, A.W.P.; FELICIO, J.C.; CASTRO, J.L.; PETTINELLI JUNIOR, A. Novos genótipos de trigo (Triticum aestivum L.) obtidos por irradiação gama. Scientia Agricola, Piracicaba, v.54, n.3, p.195202, 1997.

EMBRAPA - EMPRESA BRASILEIRA DE PESQUISA AGROPECUÁRIA. Informações Técnicas da Comissão CentroSul Brasileira de Pesquisa de Trigo e Triticale para a Safra de 2005. Londrina, 2005. 234p. (Sistemas de Produção)

GOMES, F.P. Curso de Estatística Experimental. 14 ed. Piracicaba: Nobel, 2000. 477p.

GOULART, A.C.P.; PAIVA, F.A. Controle das ferrugens do trigo com fungicidas triazóis em dose normal e em metade da dose isolados ou em mistura ao mancozeb. Fitopatologia Brasileira, Brasília, v.17, n.1, p.80-83, 1992.

LOBATO, M.T.V. Desempenho agronômico de genótipos de trigo em diferentes regiões do Estado de São Paulo, no período 2003-2005. 2006. 160p. Dissertação (Mestrado) - Instituto Agronômico, Campinas, 2006.

LOBATO, M.T.V.; CAMARGO, C.E.O.; FERREIRA-FILHO, A.W.P.; BARROS, B.C.; CASTRO, J.L.; GALLO, P.B. Avaliação de linhagens de trigo provenientes de cruzamentos interespecíficos em dois locais do Estado de São Paulo e em laboratório. Bragantia, Campinas, v.66, n.1, p.31-41, 2007. 
LOBATO, M.T.V.; CAMARGO, C.E.O.; FERREIRA FILHO, A.W.P.; BARROS, B.C.; PETTINELLI JUNIOR, A.; PEREIRA, J.C.V.N.A.; GALLO, P.B. Desempenho de linhagens de trigo mexicanas, em condição de irrigação por aspersão no Estado de São Paulo. Arquivos do Instituto Biológico, São Paulo, v.72, n.2, p.211-219, 2005.

KHAN, M.A.; TREVATHAN, L.E.; ROBBINS, J.T. Quantitative relationship between leaf rust and wheat yield in Mississipi. Plant Disease, St Paul, v.81, n.4, p.769-772, 1997.

METHA, Y.R. Manejo Integrado de Enfermidades del Trigo. Santa Cruz de la Sierra Imprenta Landivar, S. R. L., 1993. 314p.

MOORE, D.P.; KRONSTAD, W.E.; METZGER, R.J. Screening wheat for aluminum tolerance. In: WORKSHOP ON PLANT ADAPTATION TO MINERAL STRESS IN PROBLEM SOILS, Beltsville, 1976. Proceedings... Ithaca: Cornell University, 1976. p.287-295.

REIS, E.M.; CASA, R.T.: HOFFMAN, L.; MENDES, E.M. Effect of leaf rust on wherat grain yield. Fitopatologia Brasileira, Brasília, v.25, n.1, p.67-71, 2000.

ROSA, O.S.; CAMARGO, C.E. de O.; RAJARAM, S.; ZANATTA, A.C.A. Produtividade de trigo (Triticum aestivum (L.) THELL) com tolerância ao alumínio tóxico do solo. Pesquisa Agropecuária Brasileira, Brasília, v.29, n.3, p. 411-417, 1994.

SALOMON, M.V.; CAMARGO, C.E. de O.; FERREIRA-FILHO, A.W.P.; PETTINELLI-JUNIOR, A.; CASTRO, J.L. de. Desempenho de linhagens diaplóides de trigo obtidas via cultura de anteras quanto à tolerancia ao alumínio, produção de grãos e altura de planta. Bragantia, Campinas, v.62, n.2, p.189-198, 2003.

TULMANN-NETO, A.; ALVES, M.C.; CAMARGO, C.E. de O.; CASTRO, J.L. de.; FERREIRA-FILHO, A.W.P. New wheat (Triticum aestivum L.) genotypes tolerant to aluminum toxicity obtained by mutation breeding. Pesquisa Agropecuária Brasileira, Brasília, v.36, n.1, p. 61-70, 2001. 